\title{
Hepatic Glutathione Metabolism in Mice Acutely Treated with Lead Acetate
}

\author{
KazUo NAKAGAWA \\ Department of Food Sciences, Faculty of Home Economics, Kyoto Women's University, \\ Higashiyama-ku, Kyoto 605, Japan
}

Accepted June 5, 1989

\begin{abstract}
Hepatic glutathione content decreased in a dose-dependent manner after the administration of lead acetate (5-100 mg/ $\mathrm{kg}$, i.p.). Hepatic cysteine content, a substantial rate limiting factor in glutathione synthesis, also decreased transiently but significantly, whereas total cysteine (cysteine plus cystine) content remained unchanged. The pretreatment of mice with L-methionine $(250 \mathrm{mg} / \mathrm{kg}$. i.p.) partially prevented the decrease in glutathione content in lead-treated mice at least partly through the elevation of hepatic cysteine content: in contrast. L-cysteine administration $(250 \mathrm{mg} / \mathrm{kg}$. i.p.) depleted hepatic glutathione contrary to a quick increase in hepatic cysteine content. The activity of $r$-glutamylcysteine synthetase (GCS), a rate limiting enzyme in glutathione synthesis, was not altered by either the administration of lead or sulfur amino acids. On the other hand, lead facilitated the disappearance of glutathione from the livers of mice treated with buthionine sulfoximine, a specific inhibitor of GCS. These lines of evidence suggest that for the decrease in glutathione content elicited by lead-loading. the increased efflux of glutathione into extra-hepatic spaces is a more crucial event than the fluctuation of intrahepatic cysteine concentration.
\end{abstract}

In mammalian livers, glutathione has an important role in detoxification of heavy metals as well as electrophilic organocompounds $(1,2)$. Several studies have shown that the effect of inorganic lead on hepatic glutathione content varied from case to case: a single injection of lead decreased glutathione content (3). whereas long-term lead exposure increased hepatic glutathione content (4, 5). Furthermore, increased glutathione content via lead administration has resulted in reducing the toxicity of other electrophilic xenobiotics such as bromobenzene (6) or aflatoxin $B_{1}(7)$. Thus the alteration in the status of glutathione induced by lead may concern not only the occurrence of lead intoxication but the metabolic fates of other xenobiotics as well as drugs. The metabolism of glutathione under insult of lead, however, is known to a limited extent.

Although one could explain the increase in glutathione content in chronically-leadtreated mice as a compensatory response, there has been little information on events causing the difference in glutathione content between the acute and chronic administration of lead. The factors related to the exposure situation of lead or species of animals may contribute to the difference.

The present experiments were undertaken to elucidate first the alterations in hepatic glutathione metabolism in mice after acute lead administration by measuring glutathione content, cysteine content, and the activity of a key enzyme in glutathione synthesis, i.e., $r$ glutamylcysteine synthetase (GCS). In addition, the half-life of hepatic glutathione was calculated to assess the effect of lead on the efflux of glutathione out of livers by use of a glutathione synthesis inhibitor.

\section{Materials and Methods}

Drugs: Glutathione reductase (Type III), DL-buthionine sulfoximine (BSO) and disodium adenosine triphosphate were obtained from Sigma Chemical Co. (St. Louis. 
U.S.A.). All other chemicals were of the best grade available.

Animals: Male ddY strain mice, weighing 25-35 g. were purchased from Shizuoka Laboratory Animal Center (Hamamatsu. Japan), housed in a temperature-controlled environment with $12 \mathrm{hr}$ light/dark cycle, and allowed free access to rodent chow and water.

Experimental procedures: $L$-Methionine, $L$ cysteine, BSO $(6 \mathrm{mmol} / \mathrm{kg})$ and lead acetate were injected intraperitoneally. Animals were killed between 10:00 and 13:00 hr to minimize the effects of diurnal rhythms, and parallel assays were run on control groups for each experiment. After animals were killed by cervical dislocation, livers were perfused with cold $0.9 \% \mathrm{NaCl}$ solution from the portal vein. Then the livers were promptly removed and weighed.

Total glutathione (reduced plus oxidized glutathiones) was assayed by the enzymatic cycling method modified by Adams et al. (8) in the presence of $0.25 \mathrm{mM}$ bis (3-carboxy4-nitrophenyl) disulfide (DTNB). $0.22 \mathrm{mM}$ $\mathrm{NADPH}$, and glutathione reductase (1 Unit). In short. $50 \mathrm{mg}$ of liver was homogenized in 5 $\mathrm{ml}$ of $10 \mathrm{mM}$ DTNB solution and then diluted 10 -fold with $100 \mathrm{mM}$ potassium phosphate buffer ( $\mathrm{pH} 7.5$ ) containing $5 \mathrm{mM}$ ethylenediamine tetraacetic acid. After centrifugation at $2,000 \times \mathrm{g}$ for $3 \mathrm{~min}$, the supernatant was used for measurement of glutathione. The reaction was followed by monitoring the change in absorbance at $412 \mathrm{~nm}$ with a Hitachi double beam spectrophotometer. The contents of glutathione were expressed as reduced glutathione equivalents.

Cysteine in the liver, extracted with 5\% perchloric acid, was assayed spectrophotometrically according to the method of Gaitonde (9) using acid ninhydrin reagent. Total cysteine (cysteine plus cystine) was determined after cystine was reduced to cysteine by the addition of $5 \mu \mathrm{mol}$ dithiothreitol at a neutral $\mathrm{pH}$.

GCS activity in the liver was assayed spectrophotometrically according to the method of Sekura and Meister (10).

Protein was measured according to the method of Lowry et al. (11) using bovine serum albumin as the standard.

Statistical significance of the results was determined by Student's $t$-test, and $P$ values less than 0.05 were considered significant.

\section{Results}

Dose-dependent effect of lead on hepatic glutathione content: As shown in Fig. 1, the contents of glutathione (the sum of reduced and oxidized forms of glutathiones) were decreased in a dose-dependent manner $3 \mathrm{hr}$ after a single injection (i.p.) of lead acetate. Four days after the injection, hepatic glutathione contents in lead-treated mice except at a dose of $100 \mathrm{mg} / \mathrm{kg}$ were almost restored to the control level (K. Nakagawa, unpublished observation; cf. Table 2).

Intrahepatic cysteine content: Table 1 shows cysteine contents in the livers of mice treated with $100 \mathrm{mg} / \mathrm{kg}$ of lead acetate. Cysteine contents in lead-treated mice were significantly lowered $3 \mathrm{hr}$ after the injection. whereas total cysteine (cysteine plus cystine) contents were not greatly affected by lead administration. No significant effect of lead on cysteine contents was observed 4 days after the injection. Figure 2 shows temporal changes in total cysteine contents in the livers after administration of $\mathrm{L}$-methionine or $\mathrm{L}$ cysteine at a dose of $250 \mathrm{mg} / \mathrm{kg}$ (i.p.). Total cysteine contents in L-cysteine-treated mice reached maximum 30 min after the injection and declined promptly thereafter, while those

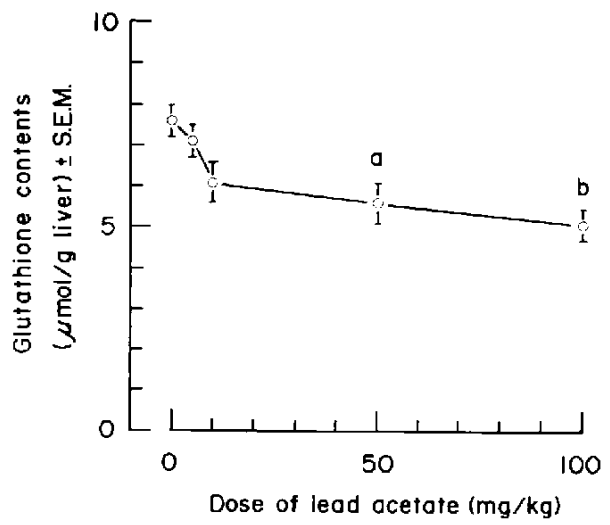

Fig. 1. Dose-dependent effect of lead acetate on glutathione content in the livers of mice. Glutathione was assayed $3 \mathrm{hr}$ after the intraperitoneal injection of lead acetate. Each point represents the mean \pm S.E.M. of 4 to 5 animals. $a P<0.05$ and $b P<0.001$. significantly different from the control. 
Table 1. Total cysteine (cysteine plus cystine) and cysteine contents in the liver after administration of lead acetate $(100 \mathrm{mg} / \mathrm{kg}$. i.p.)

\begin{tabular}{|c|c|c|}
\hline Treatment & $\begin{array}{c}\text { Total cysteine } \\
\text { (cysteine equivalents) } \\
\text { (nmol/g liver) } \pm S . E . M \text {. }\end{array}$ & $\begin{array}{c}\text { Cysteine } \\
\text { (nmol/g liver) } \pm \text { S.E.M. }\end{array}$ \\
\hline \multicolumn{3}{|l|}{3 hr after injection } \\
\hline Control (4) & $168 \pm 16$ & $149 \pm 5$ \\
\hline Lead acetate (4) & $155 \pm 5$ & $131 \pm 3^{a}$ \\
\hline \multicolumn{3}{|l|}{4 days after injection } \\
\hline Contro! (4) & $164 \pm 9$ & $140 \pm 9$ \\
\hline Lead acetate (4) & $170 \pm 11$ & $146 \pm 12$ \\
\hline
\end{tabular}

Total cysteine (cysteine plus cystine) was determined after reduction with dithiothreitol as described in the text and expressed as cysteine equivalents. Animals were killed 3 hr or 4 days after injection of lead acetate $(100 \mathrm{mg} / \mathrm{kg})$. Each figure represents the mean $=S . E . M$. of the number of animals indicated in parentheses. aP<0.05, significantly different from the control.

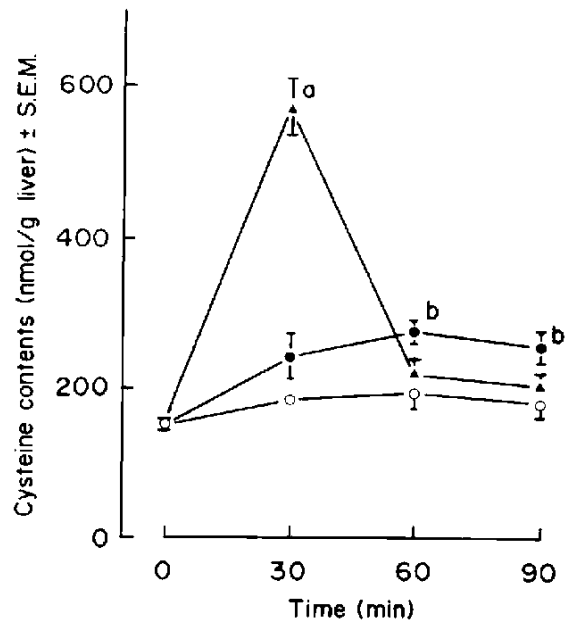

Fig. 2. The content of total cysteine (cysteine plus cystine) in the liver after intraperitoneal injection of L-methionine (250 $\mathrm{mg} / \mathrm{kg}$. O). L-cysteine (250 mg/ $\mathrm{kg} . \boldsymbol{\Delta})$ or saline $(10 \mathrm{ml} / \mathrm{kg} . \bigcirc)$. Total cysteine was expressed as cysteine equivalents. Each point represents the mean \pm S.E.M. of 4 animals. a $P<0.001$ and $\mathrm{bP}<0.05$, significantly different from the control.

in $L$-methionine-treated mice increased slowly and reached maximum $60 \mathrm{~min}$ after the injection.

Hepatic glutathione contents in mice treated with lead acetate and sulfur amino acids: The effects of pretreatment of $L$ methionine and $L$-cysteine on the decrease in hepatic glutathione contents induced by lead were examined, because the administration of these sulfur amino acids was able to raise the cysteine content. Either sulfur amino acid $(250 \mathrm{mg} / \mathrm{kg}$ ) was injected intraperitoneally $60 \mathrm{~min}$ before lead administration $(100 \mathrm{mg} /$ $\mathrm{kg}$. i.p.), and hepatic glutathione contents were determined $3 \mathrm{hr}$ and 4 days after lead administration. As shown in Table 2, glutathione content in mice treated with both methionine and lead was not statistically different from that in control or lead-treated mice. In contrast, $L$-cysteine, given alone or together with lead, diminished glutathione content greatly.

The effects of methionine pretreatment on total cysteine content and GCS activity in the livers of lead-treated mice: Figure 3 shows total cysteine contents in the livers of mice pretreated with L-methionine $(250 \mathrm{mg} / \mathrm{kg}$. i.p.) $1 \mathrm{hr}$ before lead administration (100 mg/ $\mathrm{kg})$. At early stages of the time course examined. cysteine contents in mice treated with both lead and L-methionine were higher than those in mice treated with lead alone.

The activity of GCS, a rate limiting enzyme in glutathione synthesis, in the livers of these animals was examined $3 \mathrm{hr}$ after the lead administration. Lead administration had no effect on GCS activity as indicated by the following data: the means \pm S.E.M. of GCS activities ( $\mathrm{nmol} / \mathrm{mg}$ protein/min) in mice treated with saline (control), lead $(100 \mathrm{mg} /$ $\mathrm{kg}$ ) alone, methionine $(250 \mathrm{mg} / \mathrm{kg}$ ) alone. and both methionine $(250 \mathrm{mg} / \mathrm{kg}$ ) and lead $(100 \mathrm{mg} / \mathrm{kg}$ ) were $63 \pm 14,79 \pm 8,55 \pm 9$ and $59 \pm 9$, respectively ( 5 animals for each group). 
Table 2. Total glutathione (reduced and oxidized glutathiones) content in the liver $3 \mathrm{hr}$ and 4 days after lead administration

\begin{tabular}{lcc}
\hline & \multicolumn{2}{c}{$\begin{array}{c}\text { Total glutathione content } \\
\text { (reduced glutathione equivalents) } \\
\text { ( } \mu \text { mol/g liver) } \pm \text { S.E.M. }\end{array}$} \\
Treatment & $3 \mathrm{hr}$ & 4 days \\
Saline+Saline & $8.1 \pm 0.3(17)$ & $8.4 \pm 0.3 \quad(5)$ \\
Saline+Lead & $6.1 \pm 0.3^{\mathrm{a}}(17)$ & $5.8 \pm 0.3^{\mathrm{a}}(5)$ \\
Methionine+Saline & $8.1 \pm 0.6(11)$ & $7.8 \pm 0.3 \quad(5)$ \\
Methionine+Lead & $7.1 \pm 0.6(12)$ & $6.5 \pm 0.6 \quad(5)$ \\
Cysteine+Saline & $4.2 \pm 0.6^{\mathrm{b}}(6)$ & N.D. \\
Cysteine+Lead & $3.5 \pm 0.2^{\mathrm{b}}(7)$ & N.D. \\
\hline
\end{tabular}

Sulfur amino acids were injected intraperitoneally $1 \mathrm{hr}$ before lead acetate administration $(100 \mathrm{mg} / \mathrm{kg}$, i.p.). Tota! glutathione content was expressed as reduced glutathione equivalents. Each figure represents the mean \pm S.E.M. of the number of animals indicated in parentheses. N.D., not determined. $\mathrm{a} P<0.01$ and $\mathrm{b} P<0.001$, significantly different from the saline-pretreated control.

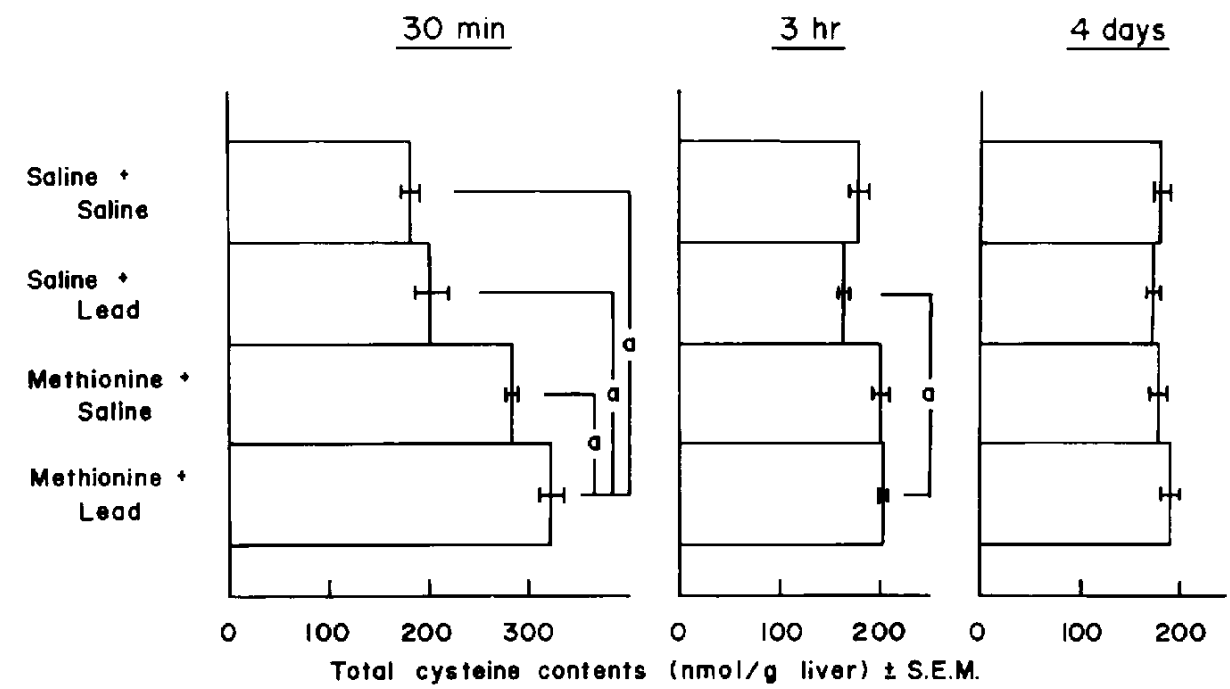

Fig. 3. The effect of L-methionine pretreatment on total cysteine content in the liver of lead-treated mice. L-Methionine $(250 \mathrm{mg} / \mathrm{kg}$, i.p.) was given $1 \mathrm{hr}$ before the administration of lead acetate $(100 \mathrm{mg} /$ $\mathrm{kg}$. i.p.). Total cysteine content in the liver, expressed as cysteine equivalents, was determined $30 \mathrm{~min}$. $3 \mathrm{hr}$ and 4 days after the injection of lead acetate. Each bar represents the mean \pm S.E.M. of 4 to 6 animals. aTied bars are significantly different at $\mathrm{P}<0.05$.

Additionally, GCS activity 4 days after lead administration $(100 \mathrm{mg} / \mathrm{kg})$ remained unchanged $(66 \pm 7 \mathrm{nmol} / \mathrm{mg}$ protein $/ \mathrm{min} \pm$ S.E.M. from six control mice vs. $76 \pm 15 \mathrm{nmol} /$ $\mathrm{mg}$ protein $/ \mathrm{min} \pm \mathrm{S}$. E.M. from six lead-treated mice).

Effect of lead on disappearance of glutathione in the liver of BSO-treated mice: Lead acetate $(100 \mathrm{mg} / \mathrm{kg})$ was injected in- traperitoneally $10 \mathrm{~min}$ after administration of BSO (6 mmol/ $\mathrm{kg}$, i.p.), a potent inhibitor of GCS. Then glutathione contents in the livers were determined $30,45,60,90$ and $120 \mathrm{~min}$ after BSO administration and plotted on a semilogarithmic graph (Fig. 4); The data indicated that lead facilitated the disappearance of glutathione from the livers. On the assumption that the elimination of g!u- 

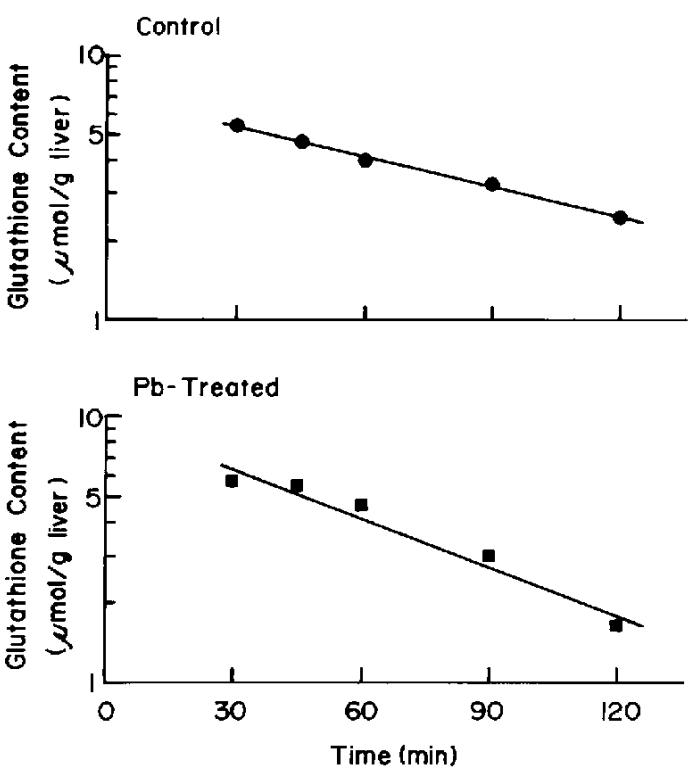

Fig. 4. Decline curve for hepatic glutathione after buthionine sulfoximine (BSO) administration. Lead acetate (100 $\mathrm{mg} / \mathrm{kg}$, i.p.) was given $10 \mathrm{~min}$ after the administration of $\mathrm{BSO}$ (6 mmol $/ \mathrm{kg}$. i.p.). Saline in place of lead was given to control animals. Each point represents the mean of 3 animals. mice treated with BSO and saline: $\square$. mice treated with BSO and lead.

tathione followed first-order kinetics, an apparent elimination half-life of hepatic glutathione was obtained graphically; the halflife of glutathione (the mean \pm S.E.M. of three separate experiments) in lead-treated mice was $49 \pm 6$ min. while that in the control was $96 \pm 15 \mathrm{~min}$. The difference between the two groups was statistically significant $(P<0.05)$. The half-life of hepatic glutathione in mice 4 days after lead administration (100 $\mathrm{mg} / \mathrm{kg}$ ) was also determined. The value, $105 \pm 28 \mathrm{~min}$ (the mean \pm S.E.M., $n=3$ ). was not statistically different from either the control value or the shortened value by lead stated above.

\section{Discussion}

Several investigators have documented that treatment of rats with lead produced increases in hepatic glutathione content $(4,6$, 7). One possible explanation for these rises in glutathione content was a compensatory mechanism supplying sufficent glutathione to overcome lead toxicity. Contrary to these re- ports, the present results show that the acute administration of lead to mice decreased hepatic glutathione content in accordance with the results in mice reported by Dalvi and Robbins (3). However, it is not clear at present whether species differences exist or not.

Diethyl maleate, the most widely-used depleting agent, has been reported to increase the hepatic glutathione content to more than normal levels after an initial depletion period (12). As for the existence of a rebound phase of glutathione content in leadtreated mice, further studies are needed. Such studies may also contribute to clarifying the discrepancy between the present results and the previous observations in glutathione content.

Since the metabolism of glutathione under lead-loading has not been understood in detail so far, effects of lead on the biosynthesis of glutathione in the liver were first examined. The activity of GCS, a key enzyme for the synthesis of glutathione, was insensitive to lead. Besides, the concentration of cysteine, a substantial rate-limiting factor in glutathione biosynthesis because of lower intracellular concentration than the apparent $K_{m}$ value of GCS for the substrate cysteine $(13,14)$, was found to be decreased only transiently in lead-treated mice. while total cysteine contents remained unchanged. Since the major metabolic fate of cystine is conversion to cysteine (15), it is unlikely that the temporary decrease in intrahepatic cysteine contents was of the first importance for the leadinduced depletion of glutathione lasting at least four days.

The increase in cysteine content was prominent in mice treated with both L-methionine and lead at early stages, indicating the rise in influx of sulfur into the glutathione synthesis pathway probably through a transsulfuration pathway in lead-treated mice. Nevertheless, the result that glutathione content in mice treated with both methionine and lead did not significantly differ from that in mice treated with lead alone implies that pretreatment of methionine was not completely successful in counteracting the decrease in glutathione in lead-treated mice. Some factors other than cysteine content are likely to concern the decrease in glutathione content 
in lead-treated mice.

On the other hand, a bolus administration of L-cysteine. which promptly produced high intrahepatic concentration of cysteine. diminished hepatic glutathione content and failed to counteract the depletion of glutathione induced by lead. The decrease in glutathione content caused by L-cysteine pretreatment may be ascribed in part to the autoxidation of cysteine, which results in consumption of glutathione by reaction with thiyl radicals and hydroxyl radicals produced in the cells (16). The production of free radical species could involve the propagation of lipid peroxidation. which possibly results in the leak of glutathione or the depression of glutathione synthesis because of damage to the cell membrane or to an apparatus such as the amino acid transport systems. These results in mice pretreated with $L$-methionine or L-cysteine also suggest that the fluctuation of intrahepatic cysteine concentration is incapable of being a primary cause responsible for the depletion of glutathione in leadtreated mice.

The present finding that lead treatment accelerated the disappearance of glutathione from the livers of BSO-treated mice seems to be a clue to clarify mechanisms underlying the alteration in glutathione metabolism in leadtreated mice. Since lead has a high affinity for glutathione (17), chelation of lead by glutathione, similar to the conjugation of electrophilic xenobiotics with glutathione, may be followed by the excretion to extrahepatic spaces. In fact, several workers have recently shown the excretion of lead into bile occurred in a glutathione dependent biological process in some species of animals $(18,19)$.

Furthermore, in relation to hepatic glutathione metabolism, the importance of glutathione translocation across cell membranes has been emphasized on the basis of the degradative pathway peculiar to this tripeptide, which is characterized by the following $(20,21)$ : degradation of glutathione occurs exclusively on the outer surface of cell membranes by $r$-glutamyltransferase and cysteinylglycine dipeptidase. whereas biosynthesis of this tripeptide proceeds intracellularly.

However, glutathione content was still low at the late stage after lead administration. when the half-life of hepatic glutathione was in the course of restoration to normal ranges, and besides, cysteine content and GCS activity were normal. This discrepancy requires further studies on the glutathione metabolism and glutathione status under the acute lead insult, with respect to topics such the cofactor for glutathione synthesis, e.g., adenosine triphosphate. and glutathione mixed disulfides with proteins.

In conclusion, the present results suggest that the facilitated efflux of glutathiones. probably including the complex of glutathione with lead, across cell membranes is a vital determinant for the depletion of hepatic glutathione in lead-treated mice.

Acknowledgments: The author thanks Ms. Y. Shikimori, Ms. K. Ohshima, Ms. S. Oka, Ms. A. Miura ano Ms. N. Ohine for their technical assistance.

\section{References}

1 Ballatori, N. and Clarkson, T.W.: Biliary secretion of glutathione and glutathione-metal complex. Fundam. Appl. Toxicol. 5, 816-831 (1985)

2 Klaassen, C.D., Braken, W.M., Dudley, R.E., Goering, P.L., Hazelton, G.A. and Hjelle, J.J.: Role of sulfhydryls in the hepatotoxicity of organic and metallic compounds. Fundam. Appl. Toxicol. 5, 806-815 (1985)

3 Dalvi, R.R. and Robbins, T.J.: Comparative studies on the effect of cadmium, cobalt, lead. and selenium on hepatic microsomal monooxygenase enzymes and glutathione levels in mice. J. Environ. Pathol. Toxicol. 1, 601-607 (1978)

4 Hsu, J.M.: Lead toxicity as related to glutathione metabolism. J. Nutr. 111, 26-33 (1981)

5 McGowan, C. and Donaldson, W.E.: Effect of lead toxicity on the organ concentration of glutathione and glutathione-related free amino acids in the chick. Toxicol. Lett. 38, 265-270 (1987)

6 Corongiu, F.P., Dore, M., Vargiolu, S., Montaldo, C., Ledda, G.M. and Congiu, L.: Bromobenzene hepatotoxicity in lead pretreated rats. Res. Commun. Chem. Pathel. Pharmacol. 15. 121133 (1976)

7 Corongiu, F.P. and Milia, A.: Rise of hepatic glutathione concentration induced in rats by chronic lead nitrate treatment. Its role in aflatoxin $B_{1}$ intoxication. Res. Commun. Chem. Pathol. Pharmacol. 38, 97-112 (1982)

8 Adams, J.D., Jr., Lauterburg, B.H. and Mitchell, 
J.R.: Plasma glutathione and glutathione disulfide in the rat: Regulation and response to oxidative stress. J. Pharmacol. Exp. Ther. 227, 749-754 (1983)

9 Gaitonde, M.K.: A spectrophotometric method for the direct determination of cysteine in the presence of other naturally occurring amino acids. Biochem. J. 104, 627-633 (1967)

10 Sekura, R. and Meister, A.: $\gamma$-Glutamylcysteine synthetase. J. Biol. Chem. 252, 2599-2605 (1977)

11 Lowry, O.H., Rosebrough, N.J., Farr, A.L. and RandalI, R.J.: Protein measurement with the Folin phenol reagent. J. Biol. Chem. 193, 265275 (1951)

12 Wirth, P.J. and Thorgeirsson, S.S.: Glutathione synthesis and degradation in fetal and adult rat liver and Novikoff hepatoma. Cancer Res. 38 . 2861-2865 (1978)

13 Tateishi, N., Higashi, T., Shinya, S., Naruse, A. and Sakamoto, $Y$ : Studies on the regulation of glutathione level in rat liver. J. Biochem. 75 . 93-103 (1974)

14 Bannai, S. and Tateishi, N.: Role of membrane transport in metabolism and function of glutathione in mammals. J. Membr. Biol. 89, 1-8 (1986)

15 Singer, T.P.: Oxidative metabolism of cysteine and cystine in animal tissues. In Metabolism of Sulfur Compounds. Edited by Greenberg. D.M.. p. 535-541. Academic Press, New York (1975)

16 Saez, G., Thornalley, P.J., Hill, H.A.O., Hems, R. and Bannister, J.J.V.: The production of free radicals during the autoxidation of cysteine and their effect on isolated rat hepatocytes. Biochim. Biophys. Acta 719, 24-31 (1982)

17 Fuhr, B.J. and Rabenstein, D.L.: Nuclear magnetic resonance studies of the solution chemistry of metal complexes. IX. The binding of cadmium. zinc, lead, and mercury by glutathione. J. Am. Chem. Soc. 95, 6944-6950 (1973)

18 Klaassen, C.D. and Shoeman, W.E.: Biliary secretion of lead in rats, rabbits and dogs. Toxicol. Appl. Pharmacol. 29, 434-446 (1974)

19 Alexander, J., Aaseth, J. and Mikalsen, A.: Excretion of lead in rat bile.-The role of glutathione. Acta Pharmacol. Toxicol. 59, 486489 (1986)

20 Inoue, M., Horiuchi, S. and Morino, Y.: $\gamma$ Glutamy! transpeptidase in ascites tumor cell LY-5. Eur. J. Biochem. 78, 609-615 (1977)

21 Horiuchi, S., Inoue, $M$. and Morino, $Y .: \gamma-$ Glutamyl transpeptidase: Sidedness of its active site on renal brush-border membrane. Eur. J. Biochem. 87, 429-437(1978) 